\title{
PERSEPSI CITRA PERUSAHAAN PERTAMBANGAN PT. BATURONA ADIMULYA MELALUI PROGRAM CORPORATE SOCIAL RESPONSIBILITY
}

\author{
Dwi Putri Lestari ${ }^{1)}$, Maulana Yusuf ${ }^{2)}$, Ridhah Taqwa ${ }^{3)}$ \\ Fakultas Teknik, Universitas Sriwijaya \\ Politeknik Akamigas Palembang \\ Fakultas Ilmu Sosial dan Ilmu Politik,Universitas Sriwijaya \\ email: putrikemassyarifudin@gmail.com
}

\begin{abstract}
Abstrak
Abstrak : Corporate Social Responsibility (CSR) merupakan bentuk komitmen sebuah perusahaan dalam menjalankan tanggung jawab sosialnya terhadap masyarakat. CSR berhubungan dengan citra perusahaan dimana terlihat pada pelaksanaan kegiatan yang dilakukan secara optimal, sehingga target program CSR dapat tercapai. PT. Baturona Adimulya sebagai perusahaan tambang telah melaksanakan berbagai macam program CSR. Penelitian bertujuan untuk melihat pengaruh program CSR terhadap citra perusahaan pertambangan PT. Baturona Adimulya. Penelitian dilakukan dengan menggunakan instrumen kuesioner yang dibagikan kepada masyarakat Ring I dari perusahaan. Hasil kuesioner yang diperoleh selanjutnya dilakukan uji validitas, realibilitas, dan normalitas dengan bantuan software Statistikal Package for the Social Sciences (SPSS). Analisis faktor dilakukan untuk melihat bagaimana pengaruh program CSR terhadap citra perusahaan. Hasil analisis menunjukkan bahwa faktor-faktor yang mempengaruhi citra perusahaan pertambangan PT. Baturona Adimulya melalui program bantuan CSR yaitu, program bantuan CSR memberikan solusi untuk membantu masyarakat (smart), perusahaan menunjukkan kinerja yang baik melalui program CSR (aloof), program bantuan CSR terorganisir dengan baik (well-organized), program bantuan CSR memberikan pengaruh baik terhadap masyarakat (wise), program CSR yang dijalankan memiliki nama baik di mata masyarakat (reputable). Program CSR yang dilakukan perusahaan memberikan pengaruh positif terhadap citra perusahaan. Persepsi masyarakat terhadap citra perusahaan melalui program CSR adalah baik dengan nilai dimensi citra tertinggi adalah character (skor rataan $=4,09$ ).
\end{abstract}

Kata kunci: faktor pengaruh, Corporate Social Responsibility (CSR), citra, perusahaan pertambangan

Abstract : Corporate Social Responsibility (CSR) is a form of commitment of a company in carrying out its social responsibility to society. CSR is related to the company's image which can be seen in the optimal implementation of activities, so that the target of the CSR program can be achieved. PT. Baturona Adimulya as a mining company has implemented various CSR programs. This study aims to analysis the effect of CSR programs on the report of the mining company PT. Baturona Adimulya. The research was conducted using a questionnaire instrument which was distributed to the Ring I community of the company. The results of the questionnaire obtained were then tested for validity, reliability, and normality with the help of the Statistical Package for the Social Sciences (SPSS) software. Factor analysis was conducted to see how the CSR program influences the company's image. The results of the analysis show that the factors that affect the image of the mining company PT. Baturona Adimulya through the CSR assistance program, namely, the CSR assistance program provides solutions to help the community (smart), the company shows good performance through the CSR program (aloof), the CSR assistance program is organized with good (well-organized), CSR assistance programs have a good influence on the community (wise), the CSR programs run have a good name in the eyes of the community (reputable). The CSR program carried out by the company has a positive influence on the company's image. Public perception of the company's image through the CSR program is good with the highest image dimension value is character (average score = 4.09).

Keywords: influence factor, Corporate Social Responsibility (CSR), image, mining company 


\section{PENDAHULUAN}

Corporate Social Responsibility (CSR) adalah bentuk komitmen tanggung jawab sosial perseroan dalam pembangunan ekonomi berkelanjutan agar kualitas kehidupan dan lingkungan meningkat dan memberikan manfaat bagi perseroan, komunitas, maupun masyarakat (Undang-undang Nomor 40 Tahun 2007). Perusahaan memandang program CSR dalam sudut pandang external driven dan internal driven. External driven memandang CSR sebagai suatu usaha untuk menaikkan citra perusahaan, dan hanya untuk memenuhi kewajiban. Perspektif internal driven CSR dimaknai sebagai sebuah kewajiban untuk berbagi bersama warga yang berada di sekitar perusahaan, agar dapat hidup berkeadilan sosial. (Partini, 2013). Menurut Meilani (2019), aktivitas pertambangan memberikan dampak terhadap kondisi sosial, ekonomi dan fisik masyarakat sehingga orientasi CSR harus bergeser kearah keberlanjutan lingkungan.

Peran korporasi dalam meningkatkan pembangunan masyarakat di sekitar wilayah kerja perusahaan harus dikembangkan dalam batasan skala program CSR perusahaan. Program CSR yang banyak dijalankan oleh perusahaan hanya memiliki pengaruh jangka pendek dengan skala yang terbatas. Program CSR seringkali dilaksanakan terbatas untuk menciptakan reputasi perusahaan yang pasif tetapi belum menyentuh permasalahan yang sesungguhnya dihadapi oleh masyarakat sekitar perusahaan. Program CSR selayaknya bisa dilaksanakan melalui pemberdayaan masyarakat sekitar industri berdasarkan pada kebutuhan yang dapat menunjang tingkat kesejahteraan dengan didukung secara penuh oleh masyarakat, pemerintah, stakeholder dan akademisi (Abdullah, 2016).

\footnotetext{
Dampak dari ketidaktercapaian program-program CSR perusahaan yaitu
}

dipengaruhi oleh faktor internal dan eksternal. Faktor internal yaitu kurangnya sosialisasi, pembinaan, pendampingan serta monitoring dan evaluasi dari pihak perusahaan terhadap program yang diberikan ke masyarakat. Faktor eksternal seperti kurangnya komitmen masyarakat penerima bantuan untuk melaksanakan program yang telah disetujui. (Oktavia et al, 2018)

PT. Baturona Adimulya (PT. BRAM) sebagai sebuah perusahaan tambang batubara di Sumatera Selatan telah menjalankan komitmennya dalam melaksanakan berbagai program CSR. Program CSR yang dilakukan oleh PT. BRAM seperti membantu pembangunan rumah ibadah, pemberian beasiswa pendidikan, mengadakan sunatan massal, pelatihan keterampilan, dan lain-lain (PT. Baturona Adimulya, 2019). Program CSR yang telah dilakukan oleh perusahaan tidak hanya memberikan manfaat bagi masyarakat, tetapi juga membangun citra baik perusahaan di mata pihak-pihak yang berkepentingan dan masyarakat sekitar.

Citra perusahaan adalah suatu persepsi dari stakeholder terhadap tindakan yang dilakukan oleh perusahaan (Kartikasari, dkk, 2017). Citra perusahaan dapat bersifat positif dan negatif, dimana tergantung dari yang ditampilkan oleh perusahaan kepada publiknya (Naufalia, 2016). Dimensi dari citra perusahaan menurut teori Shirley Harrison (Harni dan Aziz, 2018) yaitu:

1. Personality, terkait dengan karakteristik perusahaan seperti bertanggung jawab dan dapat dipercaya.

2. Reputation, terkait dengan kegiatan yang telah dilaksanakan perusahaan.

3. Value, terkait nilai atau budaya yang dipunyai perusahaan.

4. Corporate Identity, terkait identitas perusahaan slogan, logo, dan warna yang mempermudah masyarakat mengenal perusahaan. 
CSR dan citra perusahaan saling berkaitan dalam hal pelaksanaan program atau kegiatan yang dilaksanakan secara opimal sehingga mencapai target daripada program tersebut (Nurjanah, dkk, 2018). Pelaksanaan CSR yang optimal akan memberikan pengaruh positif terhadap citra perusahaan dan sebaliknya.

Berdasarkan hal tersebut dilakukan penelitian terkait pengaruh program CSR yang sudah dilakukan terhadap citra perusahaan PT. Baturona Adimulya di mata masyarakat.

\section{METODE PENELITIAN}

Penelitian dilaksanakan di wilayah Ring 1 PT. Baturona Adimulya yaitu desa Supat Barat, Kecamatan Babat Supat, Kabupaten Musi Banyuasin, Provinsi Sumatera Selatan. Lokasi penelitian dilakukan dengan pertimbangan bahwa desa tersebut berada pada lokasi operasional perusahaan yang terkena dampak langsung dari jalan angkut batubara PT. Baturona Adimulya. Peta lokasi dan kesampaian daerah dilihat pada Gambar 1.

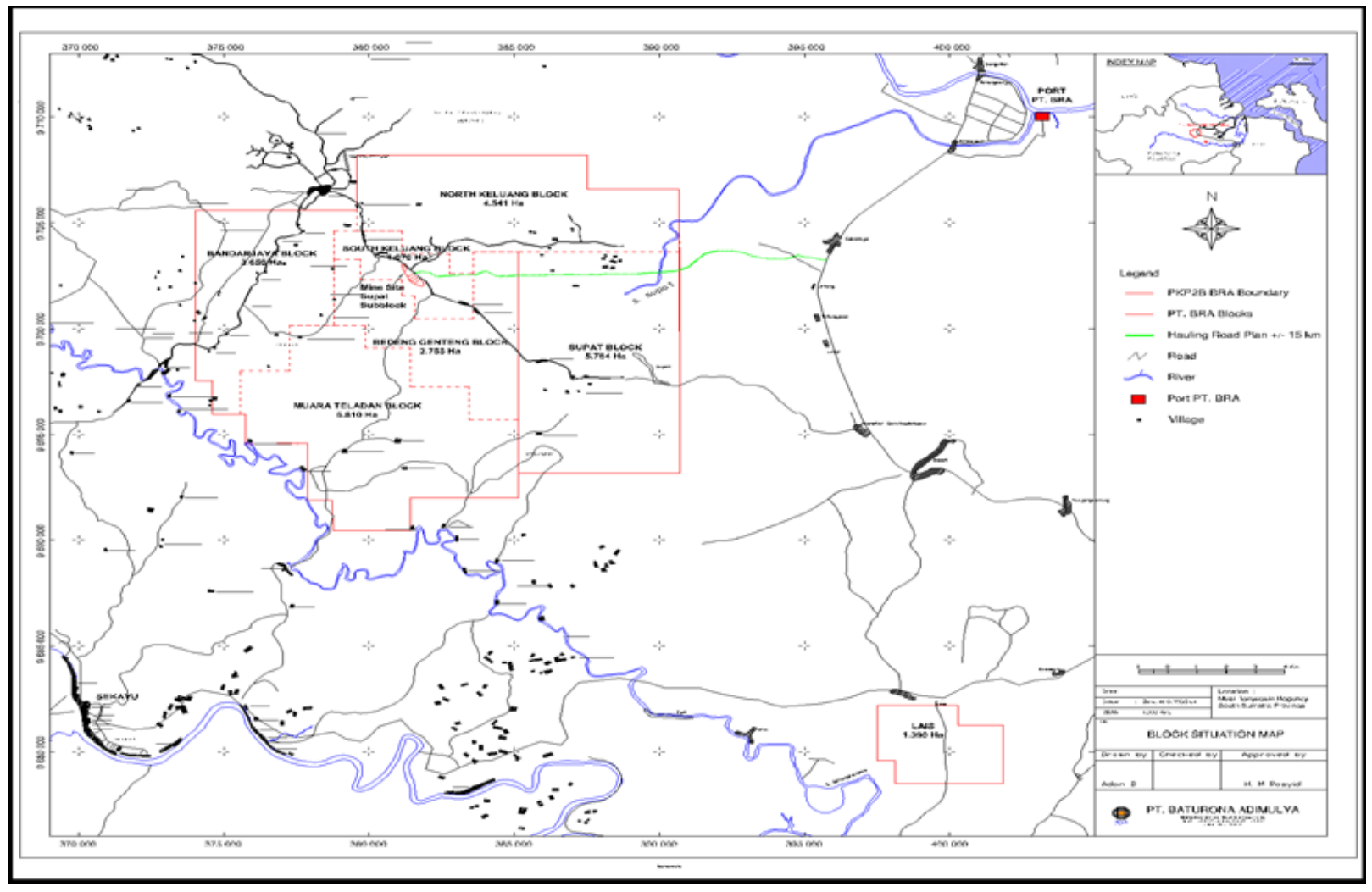

Gambar 1. Peta Lokasi dan Kesampaian Daerah (Jumiya, 2016)

Sampel pada penelitian ini adalah masyarakat desa Supat Barat yang berada pada wilayah Ring I PT. Baturona Adimulya dengan jumlah sampel sebanyak 92 orang dari total pemduduk 1177 orang. Jumlah ini diperoleh dengan menggunakan rumus Slovin dengan nilai $e$ sebesar $10 \%$ (nilai kritis untuk penelitian deskriptif).
Kerangka metodologi dalam penelitian ini sebagai berikut. 


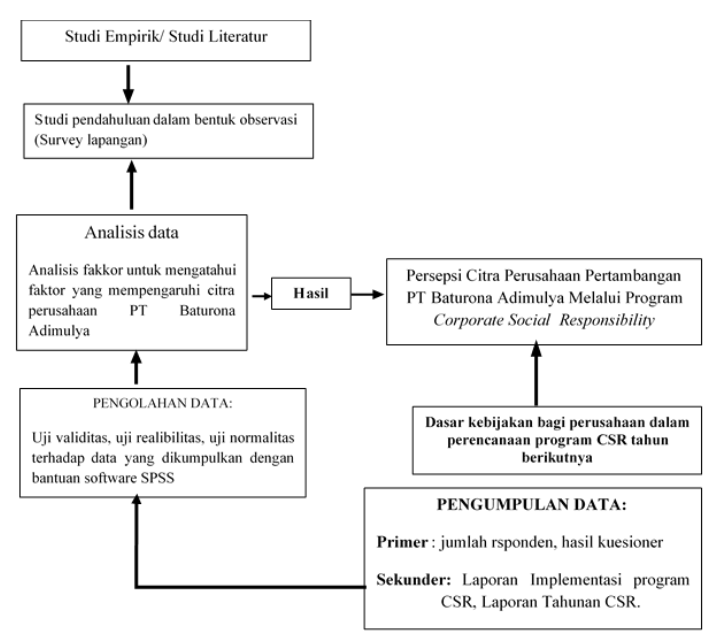

Gambar 2. Kerangka Metodologi

Pengumpulan data dilakukan dengan menggunakan bantuan instrumen kuesioner yang disebarkan ke masyarakat. Lembar kuesioner dengan menggunakan skala Likert karena paling mudah dalam memperoleh nilai dari pemanfaat atau penerima bantuan yaitu dengan menggunakan rentang angka 1 hingga 5 sehingga nilai dalam skala nominal tersebut dapat disubstitusikan menjadi kategori kualitatif ataupun sebaliknya (Prayogo, 2011).

Pengolahan data dengan melakukan beberapa uji yaitu:

\section{Uji Validitas}

Uji validitas diartikan sebagai ukuran yang menampilkan sejauh mana instrumen pengukur mampu mengukur apa yang akan diukur (Triana \& Widyarto, 2013). Uji validitas dilakukan dengan memakai rumus korelasi Product Moment Pearson berikut:

$$
r=\frac{n \sum X Y-\left(\sum X\right)\left(\sum Y\right)}{\sqrt{\left\{n \sum X^{2}-\left(\sum X\right)^{2}\right\}\left\{n \sum Y^{2}-\left(\sum Y\right)^{2}\right\}}}
$$

Keterangan :

$\mathrm{r}$ : koefisien reliabilitas yang dicari

$\mathrm{N}$ : jumlah responden

$\mathrm{X}$ : skor masing-masing pertanyaan

$\mathrm{Y}$ : skor total

Validitas dipakai untuk mengukur ketepatan kuesioner terhadap variablevariabel pertanyaannya. Pada uji validitas, akan digunakan nilai koefisien pearson. Suatu item pertanyaan pada kuesioner dikatakan valid jika nilai r-hitung lebih besar dari r-tabel. (r-hitung > r-tabel).

2. Uji Reliabilitas

Pengujian reliabilitas data memakai metode Cronbach's Alpha yaitu dilakukan untuk jenis data interval (Triana \& Widyarto, 2013) dengan rumus berikut:

$$
\propto=\mathrm{r}_{\mathrm{ii}}=\left(\frac{\mathrm{k}}{\mathrm{k}-1}\right)\left(1-\frac{\sum \mathrm{s}_{\mathrm{b}}^{2}}{\mathrm{~S}_{\mathrm{tot}}^{2}}\right)
$$

Keterangan :

rii : koefisien reliabilitas yang dicari

$\mathrm{k} \quad$ : jumlah butir instrumen

$S_{b}^{2} \quad$ : varians butir

$S_{\text {tot }}^{2}$ : varians total

Apabila $\mathrm{r}_{\text {hitung }}$ positif dan lebih besar dari nilai $r_{\text {tabel }}$ dan nilai alpha cronbach minimum adalah 0.6 maka pernyataan dalam kuesioner reliabel. Pengujian reliabilitas diolah dengan menggunakan software SPSS (Statistical Package for Social Sciences).

\section{Uji Normalitas}

Plot probabilitas normal adalah salah satu cara mendeteksi normalitas. Setiap nilai pengamatan melalui plot ini dipasangkan dengan nilai harapan dari distribusi normal. Jika residual berasal dari distribusi normal, maka nilai-nilai data (titik-titik dalam grafik) akan terletak di sekitar garis diagonal.

Analisis data dengan menggunakan analisis faktor. Analisis faktor merupakan suatu metode yang dapat mereduksi sekumpulan variabel-variabel asli (original variables) menjadi beberapa variabel baru yang disebut dengan faktor atau dimensi (Hair, 2010). Analisis faktor berusaha menghasilkan faktor atau dimensi dengan minimum lost of information. Analisis faktor berasal dari data primer yaitu, kuesioner (angket) untuk mengkuantitatifkan data dengan 
menggunakan skala likert serta menggunakan rata-rata pembobotan sebagai data statistik yang diolah.

\section{HASIL DAN PEMBAHASAN}

\section{Uji Validitas}

Uji validitas adalah uji kelayakan item yang akan digunakan dalam penelitian secara tepat dan cermat. Pengujian kuesioner mengenai program CSR PT. BRAM dan citra perusahaan dilakukan terhadap 30 responden pada awal penelitian. Nilai korelasi antara skor masing-masing pertanyaan dengan skor total dihitung dengan menggunakan rumus teknik korelasi Product Moment Pearson dengan bantuan software Microsoft Statistical Package for Social Science (SPSS).

Hasil pengujian kuesioner dinyatakan valid atau tidak valid untuk dijadikan alat ukur antara tingkat kepentingan dan tingkat kinerja terhadap seluruh pertanyaan apabila $\mathrm{r}_{\text {hitung }}$ lebih besar dari $\mathrm{r}_{\text {tabel }}$ pada selang 95\% sebesar 0.361 (pada uji 2 arah). Setelah dilakukan uji validitas terhadap 30 orang, tidak diperoleh pertanyaan yang tidak valid pada kuesioner yang akan digunakan pada penelitian, sehingga kuesioner dapat disebar kepada 92 orang responden. Berdasarkan hal tersebut dapat disimpulkan bahwa responden memahami tujuan setiap pertanyaan dalam kuesioner. Hasil uji validitas instrumen citra PT. BRAM disajikan pada Tabel 1.

Tabel 1. Uji Validitas Instrumen Citra

$$
\text { PT. BRAM }
$$

\begin{tabular}{|c|c|c|c|c|c|}
\hline No & Kode & Variabel & $\begin{array}{l}\text { Nilai } \\
\mathbf{r}_{\text {hitung }}\end{array}$ & $\begin{array}{c}\text { Nilai } \\
\mathbf{r}_{\text {tabel }}\end{array}$ & Keterangan \\
\hline \multicolumn{6}{|c|}{ Dynamic } \\
\hline 1 & $\mathrm{C} 1$ & $\begin{array}{l}\text { Program CSR } \\
\text { telah menarik } \\
\text { perhatian } \\
\text { masyarakat } \\
\text { (attention- } \\
\text { getting) }\end{array}$ & 0.87 & 0.361 & Valid \\
\hline
\end{tabular}

\begin{tabular}{|c|c|c|c|c|c|}
\hline No & Kode & Variabel & $\begin{array}{l}\text { Nilai } \\
\mathbf{r}_{\text {hitung }}\end{array}$ & $\begin{array}{c}\text { Nilai } \\
\mathbf{r}_{\text {tabel }}\end{array}$ & Keterangan \\
\hline 2 & $\mathrm{C} 2$ & $\begin{array}{l}\text { Aktif dalam } \\
\text { melaksanakan } \\
\text { program CSR } \\
\text { (active) }\end{array}$ & 0.84 & 0.361 & Valid \\
\hline 3 & $\mathrm{C} 3$ & $\begin{array}{l}\text { Program CSR } \\
\text { PT BRAM } \\
\text { memiliki } \\
\text { tujuan yang } \\
\text { jelas (goal } \\
\text { oriented) }\end{array}$ & 0.70 & 0.361 & Valid \\
\hline \multicolumn{6}{|c|}{ Cooperative } \\
\hline 4 & $\mathrm{C} 4$ & $\begin{array}{l}\text { Menjalin } \\
\text { hubungan baik } \\
\text { dengan } \\
\text { masyarakat } \\
\text { (friendly) }\end{array}$ & 0.84 & 0.361 & Valid \\
\hline 5 & $\mathrm{C} 5$ & $\begin{array}{l}\text { Pelaksanaan } \\
\text { Program CSR } \\
\text { PT. BRAM } \\
\text { telah mendapat } \\
\text { simpati dari } \\
\text { masyarakat } \\
\text { (well-liked) }\end{array}$ & 0.80 & 0.361 & Valid \\
\hline 6 & C6 & $\begin{array}{l}\text { Program } \\
\text { bantuan } \\
\text { membantu } \\
\text { memenuhi } \\
\text { kebutuhan } \\
\text { masyarakat } \\
\text { (eager to } \\
\text { please good } \\
\text { relations) } \\
\end{array}$ & 0.82 & 0.361 & Valid \\
\hline \multicolumn{6}{|c|}{ Business Wise } \\
\hline 7 & $\mathrm{C} 7$ & $\begin{array}{l}\text { Program } \\
\text { bantuan } \\
\text { memberikan } \\
\text { pengaruh baik } \\
\text { terhadap } \\
\text { masyarakat } \\
\text { (wise) } \\
\end{array}$ & 0.69 & 0.361 & Valid \\
\hline 8 & $\mathrm{C} 8$ & $\begin{array}{l}\text { Program } \\
\text { bantuan } \\
\text { memberikan } \\
\text { solusi untuk } \\
\text { membantu } \\
\text { masyarakat } \\
(\text { smart }) \\
\end{array}$ & 0.76 & 0.361 & Valid \\
\hline 9 & C9 & $\begin{array}{l}\text { Mampu } \\
\text { mengajak } \\
\text { masyarakat } \\
\text { untuk } \\
\text { berpartisipasi } \\
\text { dalam program } \\
\text { (persuade) }\end{array}$ & 0.71 & 0.361 & Valid \\
\hline 10 & $\mathrm{C} 10$ & $\begin{array}{l}\text { Program } \\
\text { bantuan } \\
\text { terorganisir } \\
\text { dengan baik } \\
\text { (well- } \\
\text { organized) }\end{array}$ & 0.82 & 0.361 & Valid \\
\hline \multicolumn{6}{|c|}{ Character } \\
\hline 11 & $\mathrm{C} 11$ & $\begin{array}{l}\text { Program CSR } \\
\text { PT. BRAM } \\
\text { dilaksanakan } \\
\text { secara etis di } \\
\text { masyarakat } \\
\text { (ethical) } \\
\end{array}$ & 0.55 & 0.361 & Valid \\
\hline 12 & $\mathrm{C} 12$ & $\begin{array}{l}\text { Program yang } \\
\text { dijalankan } \\
\text { memiliki nama } \\
\text { baik di mata }\end{array}$ & 0.61 & 0.361 & Valid \\
\hline
\end{tabular}




\begin{tabular}{|c|c|c|c|c|c|}
\hline No & Kode & Variabel & $\begin{array}{l}\text { Nilai } \\
\mathbf{r}_{\text {hitumg }}\end{array}$ & $\begin{array}{c}\text { Nilai } \\
\mathbf{r}_{\text {tabel }}\end{array}$ & Keterangan \\
\hline & & $\begin{array}{l}\text { masyarakat } \\
\text { (reputable) }\end{array}$ & & & \\
\hline \multicolumn{6}{|c|}{ Successful } \\
\hline 13 & $\mathrm{C} 13$ & $\begin{array}{l}\text { Membantu } \\
\text { memecahkan } \\
\text { permasalahan } \\
\text { yang dihadapi } \\
\text { perusahaan dan } \\
\text { masyarakat } \\
\text { (self- } \\
\text { confidence) }\end{array}$ & 0.87 & 0.361 & Valid \\
\hline 14 & C14 & $\begin{array}{l}\text { Program CSR } \\
\text { telah membuat } \\
\text { PT BRAM } \\
\text { menjadi lebih } \\
\text { produktif } \\
\text { (financial } \\
\text { performance) } \\
\end{array}$ & 0.63 & 0.361 & Valid \\
\hline \multicolumn{6}{|c|}{ Withdrawn } \\
\hline 15 & C15 & $\begin{array}{l}\text { PT BRAM } \\
\text { telah } \\
\text { menunjukkan } \\
\text { kinerja yang } \\
\text { baik melalui } \\
\text { program CSR } \\
\text { (aloof) } \\
\end{array}$ & 0.75 & 0.361 & Valid \\
\hline 16 & $\mathrm{C} 16$ & $\begin{array}{l}\text { PT BRAM } \\
\text { merahasiakan } \\
\text { kegiatan CSR } \\
\text { yang sedang } \\
\text { dilakukannya } \\
\text { (secretive) }\end{array}$ & 0.76 & 0.361 & Valid \\
\hline 17 & $\mathrm{C} 17$ & $\begin{array}{l}\text { PT BRAM } \\
\text { berhati-hati } \\
\text { dalam } \\
\text { melaksanakan } \\
\text { seluruh } \\
\text { kegiatan CSR } \\
\text { (cautious) }\end{array}$ & 0.64 & 0.361 & Valid \\
\hline
\end{tabular}

Berdasarkan Tabel 1 di atas, dapat diketahui bahwa tidak ada nilai pada kolom $r_{\text {hitung }}$ lebih kecil dari $r_{\text {tabel }}=$ 0.361. Hasil tersebut menunjukkan bahwa seluruh variabel penelitian valid, untuk selanjutnya dilakukan uji reliabilitas.

\section{Uji Reliabilitas}

Uji reliabilitas adalah pengujian terhadap konsistensi alat ukur sehingga alat ukur tersebut dapat digunakan juga dalam pengujian berulang berikutnya. Pengujian reliabilitas yang digunakan dalam penelitian ini adalah metode Cronbach's Alpha, dimana variabel penelitian dikatakan reliabel bila nilai $\mathrm{r}$ alpha lebih besar dari 0,7 (Halin, 2018).

Hasil uji reliabilitas sikap responden terhadap citra PT. BRAM menghasilkan nilai $\alpha=0.948$. Nilai $\alpha_{\text {cronbach }}$ yang hampir mendekati 1 mengindikasikan bahwa kemungkinan terjadi kesalahan pengukuran dalam kuesioner cukup rendah dan penggunaannya dapat diandalkan serta dapat digunakan berulang kali.

\section{Uji Normalitas}

Uji normalitas untuk mengetahui apakah variable dependen, independen atau keduanya berdistribusi normal, mendekati normal atau tidak. Model regresi yang baik hendaknya berdistribusi normal atau mendekati normal. Jika data menyebar di sekitar garis diagonal dan mengikuti arah garis diagonalnya, model regresi memenuhi asumsi normalitas.

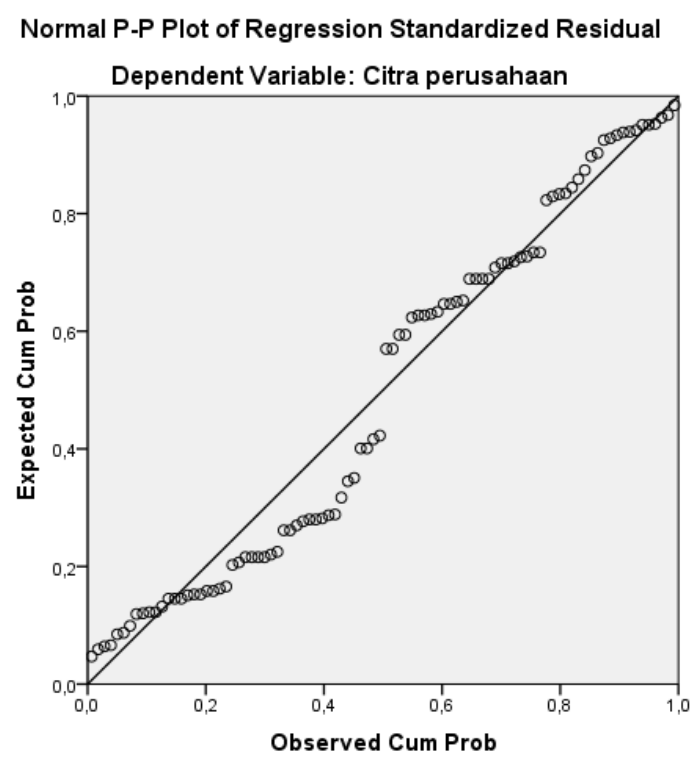

Gambar 3. Hasil Uji normalitas (P-Plot)

Berdasarkan hasil uji normalitas probability plot menggunakan program SPSS pada gambar 3, sebaran data yang telah diolah terlihat menyebar disekitar garis diagonal maka dapat diasumsikan bahwa data yang digunakan terdistribusi normal.

\section{Uji Analisis Faktor}

Menurut Hair dalam Yasa et al, (2017), Analisis faktor merupakan suatu metode yang dapat mereduksi sekumpulan variabel-variabel asli 
(original variables) menjadi beberapa variabel baru yang disebut dengan faktor atau dimensi. Analisis faktor berusaha menghasilkan faktor atau dimensi dengan minimum lost of information. Pengujian dengan menggunakan analisis faktor dapat menggunakan data yang berasal dari data primer maupun data sekunder. Analisis faktor berasal dari data primer yaitu, melalui penyebaran kuesioner (angket) untuk mengkuantitatifkan data dengan menggunakan skala likert serta menggunakan rata-rata pembobotan sebagai data statistik yang diolah.

\section{Faktor Yang Mempengaruhi Citra Perusahaan PT. Baturona Adimulya}

Setelah dilakukan berbagai uji terhadap hasil kuesioner, maka selanjutnya dilakukan analisis faktor. Berdasarkan analisis faktor yang dilakukan diperoleh 5 (lima) faktor yang mempengaruhi citra perusahaan PT. BRAM. Faktor yang berpengaruh terhadap citra perusahaan yaitu :

a. Program bantuan CSR memberikan solusi untuk membantu masyarakat (smart).

Program bantuan CSR yang dilaksanakan PT. BRAM telah dinilai masyarakat memberikan solusi dalam menyelesaikan permasalahan di desa Supat Barat, baik permasalahan lingkungan dan sosial yang timbul akibat adanya aktivitas pertambangan.

“...PT. BRAM sudah memberikan bantuan kepada kami dalam bentuk hibah tanah seluas 2 hektar yang nantinya akan dibangun fasilitas bangunan desa, ini sudah cukup bagi kami untuk menjadikan pondasi awal bagi struktur desa kami yang mengalami pemekaran dari desa Supat Induk sebelumnya..." $(K S B, 01)$
“...Kami terbantukan secara ekonomi sebagai warga supat barat yang bekerja di PT BRAM, selain itu kami sebagai pekerja menerima bantuan berupa jaminan kesehatan..." (KPT, 06)

Desa Supat Barat merupakan desa yang mengalami pemekaran sejak tahun 2017 dari desa Supat Induk, Desa Supat Barat terdiri dari beberapa dusun yaitu dusun 1 (satu) sampai dengan dusun 5 (lima) yang masing-masing dikepalai oleh seorang kadus (kepala dusun). Perusahaan sebagai pihak korporasi yang memiliki tanggung jawab sosial terhadap desa Supat Barat yang berada pada Ring 1 pemetaan wilayah CSR perusahaan memberikan bentuk bantuan berupa hibah tanah seluas 2 hektar kepada masyarakat desa Supat Barat. Hibah tanah yang diberikan perusahaan yang nantinya akan dibangun fasilitas perkantoran desa dan olahraga, serta memberikan bantuan berupa alat berat excavator sebagai alat yang digunakan dalam pembukaan lahan hibah tersebut.

b. Perusahaan menunjukkan kinerja yang baik melalui program CSR (aloof)

Penentuan program bantuan CSR PT. BRAM dilakukan melalui departemen khusus untuk melaksanakan program CSR yaitu departemen PPM (Pengembangan Pemberdayaan Masyarakat), Hal ini diharapakan agar terjadi kesesuaian antara kesesuaian program yang dilaksanakan perusahaan dengan kebutuhan masyarakat desa. Bantuan yang diberikan sebagiannya merupakan permintaan langsung dari warga dengan mekanisme pengajuan proposal kepada CSR PT. BRAM, 
ada pula beberapa program yang merupakan inisiatif dari CSR PT. BRAM yaitu dengan cara melakukan koordinasi pada pekerja yang berasal dari Desa Supat Barat untuk memetakan bentuk bantuan yang dibutuhkan (social mapping), sehingga program yang diberikan memang sesuai dengan harapan warga.

“...Perusahaan untuk menentukan program CSR biasanya akan melakukan survey terlebih dahulu, melalui pekerja PT. BRAM yang berasal dari daerah masingmasing..." (KPT, 8)

"...Kami mengajukan pertemuan dan rapat perangkat desa, lalu kami mengajukan proposal bantuan ke perusahaan sesuai dengan kebutuhan warga..." $(K S, 25)$

PT. BRAM dalam penentuan sasaran program CSR dengan melandaskan 5 (lima) aspek yaitu :

1) Adanya komunitas masyarakat sebagai target program yang mendiami suatu kawasan dimana operasi perusahaan dijalankan. Desa Supat Barat merupakan wilayah pemetaan CSR yang berada pada Ring 1 (satu) PT. BRAM, sehingga yang menjadi penerima manfaat program CSR adalah komunitas yang berada pada desa Supat Barat yaitu komunitas PKK, dan Karang Taruna, tokoh masyarakat, dan lembaga desa.

2) Adanya sumber daya yang berasal dari kawasan dimana sebuah komunitas berada. Sumber daya tersebut sebaiknya memang diangkat dari kearifan lokal sehingga memiliki keunggulan komparatif, sehingga program dapat dilaksanakan tepat guna dan sasaran. Masyarakat desa Supat Barat mayoritas bekerja sebagai petani karet, adanya pelatihan serta pendampingan sangat dibutuhkan masyarakat dalam pemanfaatan biji karet sebagai khas makanan desa supat barat.

3) Adanya upaya sistematis dan terukur dengan Logical Frame working yang jelas sehingga program pemberdayaan dapat benar-benar berjalan dengan baik dan memiliki tingkat sustainabilitas yang tinggi pula yang memungkinkan kemandirian masyarakat dapat terwujud.

4) Adanya target yang hendak dicapai baik dalam jangka pendek, panjang maupun menengah. Progres pencapaian target kerja CSR ini dapat diukur berdasarkan dimensi waktu sejak program tersebut dimulai.

c. Program bantuan CSR terorganisir dengan baik (well-organized)

Masyarakat desa Supat Barat sebagai subjek penerima manfaat dari program bantuan CSR yang dilaksanakan setiap tahunnya, yaitu perayaan hari besar keagamaan, hari besar nasional dan lain sebagainya.

d. Program bantuan CSR memberikan pengaruh baik (wise)

Dampak program CSR terhadap kesejahteraan masyarakat desa Supat Barat sejalan dengan fakta bahwa desa Supat Barat merupakan desa pemekaran dari desa Supat Induk pada tahun 2012. Bantuan yang diberikan CSR PT. BRAM bagi mereka cukup besar untuk mengakibatkan perubahan infrastruktur desa yang signifikan 
dalam kehidupan keseharian mereka.

“...Sebelum adanya bantuan dari PT. BA, desa kami cuma punya mushola yang terbuat dari papan, Alhamdulillah semenjak adanya bantuan dari PT. BA sudah ada masjid di Desa kami...". (WSB, 22)

“...Tadinya kita ga punya tanah untuk membangun fasilitas olahraga untuk desa, PT. BA memberikan hibah tanah 2 hektar ke desa kami untuk dibangun fasilitas olahraga untuk desa Supat Barat..."(WSB, 14)

e. Program CSR memiliki nama baik di mata masyarakat (reputable)

PT. BRAM dalam tahap perencanaan program menggunakan cara social mapping. PT. BRAM melalui social mapping, menemu kenali berbagai hal yang menjadi bagian instrinsik community dengan mendapatkan informasi sangat penting dari karakteritik komunitas untuk melihat sisi sosiologi, sehingga nantinya tahapan-tahapan dalam peristiwa adopsi sesuatu yang baru seperti munculnya pengetahuan tentang sesuatu melalui sebuah kesadaran, penerimaan dan aplikasi dapat terwujud secara efektif.

Social mapping juga merupakan upaya menggali potensi sumberdaya, kapasitas sosial maupun potensi konflik sosial sehingga menghasilkan suatu program yang profitble dan tidak bertentangan dengan kultur yang ada sehingga tingkat social risk menurun.

\section{Persepsi Responden terhadap Citra PT. Baturona Adimulya}

Hasil pengolahan data berdasarkan jawaban responden terhadap citra perusahaan menunjukkan bahwa sebagian besar responden menilai baik citra perusahaan yang dibangun melalui kegiatan CSR. Terdapat 6 (enam) indikator untuk mengukur citra perusahaan pada penelitian ini (Hardiani, 2016), seperti yang telah dijabarkan pada metode penelitian. Rekapitulasi hasil penilaian responden terhadap masing-masing indikator tersebut dapat dilihat pada tabel 2 sebagai berikut.

Tabel 2. Rekapitulasi Penilaian Responden Terhadap Citra PT. Baturona Adimulya Melalui Kegiatan CSR

\begin{tabular}{llll}
\hline No & Dimensi Citra & Skor Rataan & Kategori \\
\hline 1 & Dynamic & 3.71 & Baik \\
2 & Cooperative & 3.78 & Baik \\
3 & Business Wise & 3.49 & Baik \\
4 & Character & 4.09 & Sangat baik \\
5 & Successful & 3.45 & Baik \\
6 & Withdrawn & 3.37 & Baik \\
\hline
\end{tabular}

Berdasarkan data tersebut dapat disimpulkan bahwa penilaian responden rata-rata termasuk dalam kategori baik terhadap citra PT. BRAM melalui kegiatan CSR dengan rentang nilai 3.37 - 4.09. Dimensi Character merupakan dimensi yang memiliki nilai paling tinggi yaitu 4.09 dengan kategori sangat baik.

Dimensi Character sendiri memiliki penilaian yang tinggi dikarenakan program CSR tersebut dilaksanakan secara etis di tengah masyarakat (ethical), sehingga tercipta hubungan saling kepercayaan antara masyarakat dengan perusahaan. Program CSR telah memiliki pengaruh baik terhadap masyarakat dalam meringankan beban masyarakat untuk mencapai taraf kesejahteraan setidaknya hasil programprogram CSR akan selalu dapat 
digunakan oleh masyarakat dalam kegiatan sehari-hari.

Penilaian terendah pada dimensi Withdrawn. Pada dimensi Withdrawn mendapati nilai sebesar 3.37 yaitu sebagai nilai yang paling rendah diantara dimensi lainnya. Withdrawn diartikan sebagai suatu penilaian masyarakat terhadap kinerja yang kurang ketat dari perusahaan dalam penentuan penerima manfaat program CSR.

\section{KESIMPULAN}

1. Masyarakat menilai perusahaan memiliki citra yang baik dengan skor rataan 3.64 dan dinilai sangat baik pada dimensi character dengan skor tertinggi 4.09. Pada dimensi Character sendiri memiliki penilaian yang tinggi dikarenakan program CSR tersebut dilaksanakan secara etis di tengah masyarakat (ethical), sehingga tercipta hubungan saling kepercayaan antara masyarakat dengan perusahaan. Program CSR telah memiliki pengaruh baik terhadap masyarakat dalam meringankan beban masyarakat untuk mencapai taraf kesejahteraan setidaknya hasil program-program CSR akan selalu dapat digunakan oleh masyarakat dalam kegiatan sehari-hari.

2. Faktor-faktor yang mempengaruhi citra perusahaan pertambangan PT. Baturona Adimulya melalui program bantuan CSR, dilakukan dengan kuesioner ke 92 responden, dengan 17 variabel dan dianilisis menggunakan analisis faktor maka didapatkan 5 (lima) faktor yang mempengaruhi citra perusahaan di PT. Baturona Adimulya yaitu; program bantuan CSR memberikan solusi untuk membantu masyarakat, PT. Baturona Adimulya menunjukkan kinerja yang baik melalui program CSR, program bantuan CSR terorganisir dengan baik, program bantuan CSR memberikan pengaruh baik terhadap masyarakat, dan program CSR yang dijalankan memiliki nama baik di mata masyarakat.

\section{DAFTAR PUSTAKA}

Abdullah. Corporate Social Responsibility: Pencitraan dan Transparansi Dunia Industri. Seminar ASEAN, 2nd Psychology \& Humanity Psychology Forum UMM, 19 - 20 Februari 2016. pp: 18-22. (2016).

Halin, H. Pengaruh Kualitas Produk Terhadap Kepuasaan Pelanggan Semen Baturaja Di Palembang Pada Semen Baturaja (Persero) Tbk. Jurnal Ecoment Global., 3(2): 167-182. (2018).

Harni, D., Azis, E. Pengaruh Corporate Social Responsibility (CSR) Terhadap Citra Perusahaan PT. Bank Danamon Indonesia Tbk. Jurnal Wacana Ekonomi, 17(03): 010-018. (2018).

Hardiani. Pengaruh Corporate Social Responsibility (CSR) Terhadap Brand Image (Citra Perusahaan), Jurnal Ilmiah BONGAYA (Manajemen \& Akuntansi), XIX : 50-56. (2016).

Jumiya. Analisis Implementasi Dan Hambatan Pelaksanaan Corporate Social Responsibility (CSR) Pada PT Baturona Adimulya. Skripsi. Universitas Muhammadiyah Palembang. (2016).

Kartikasari, N. V., Hidayat, K., dan Yulianto, E. Pengaruh Corporate Social Responsibility (CSR) Terhadap Citra Perusahaan Multinasional (Survei Pada Konsumen Unilever Indonesia Mengenai Program "Project Sunlight" PT Unilever Indonesia Tbk.). Jurnal Administrasi Bisnis. 43 (1): 8-16. (2017).

PT Baturona Adimulya. Laporan CSR Tahunan PT Baturona Adimulya Tahun 2015-2019. (2019). 
Meilani, Y. F. C. P. Mengintegrasikan Nilai Sosial dan Finansial dari Perspektif Perusahaan. Prosiding Seminar Bisnis Magister Manajemen. (2019).

Naufalia, V. Pengaruh Corporate Social Responsibility terhadap Citra Perusahaan di PT Telekomunikasi Indonesia, Tbk . Jurnal Utilitas, 2 (2): 109-116. (2016).

Nurjanah, R., Mulazid, A. S. Pengaruh Kualitas Pelayanan dan Corporate Social Responsibility terhadap Citra Perusahaan. Jurnal Muqtasid, 9(1): 40-53. (2018).

Oktavia, M., Yusuf, M., Saptawan, A. The Impact Implementation Program of Corporate Social Responsibility of PT. Kuansing Inti Makmur Toward Society Development Around Mining Area. Sriwijaya Journal of Environemnt, 3(1):37-42 (2018).

Partini. CSR dan Pemberdayaan Masyarakat (Studi Implementasi CSR-PTBA di Muara Enim, Sumatera Selatan). Jurnal Manusia dan Lingkungan, 20 (1): 84-99. (2013).

Prayogo, D,. Evaluasi Program Corporate Social Responsibility dan Community Pada Industri Tambang dan Migas. Makara, Sosial Humaniora, 15(1): 43-58. (2011).

Triana, D., Oktavianto, W. O. Relevansi Kualifikasi Kontraktor Bidang Teknik Sipil Terhadap Kualitas Pekerjaan Proyek Konstruksi di Provinsi Banten. Jurnal Fondasi, 1(1): 182-190. (2013)

Republik Indonesia. Undang - undang Republik Indonesia No. 40 Tahun 2007 Tentang Perseroan Terbatas. (2007).
Yasa, I. P. A., Suciptawati, N. L. P., Susilawati, M. Implementasi Analisis Faktor Dalam Menganalisis Kepuasaan Nasabah Terhadap Kualitas Layanan (Studi Kasus : LPD Sidakarya). E- Jurnal Matematika, vol. 6 (2): 152-160 (2017). 